\title{
Extracranial internal carotid aneurysm masquerading as a parapharyngeal tumour
}

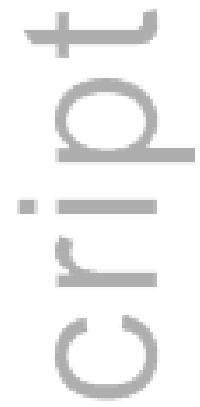

1. Dayu Gai MBBS

2. Christopher Burgess FRCS

3. Christine Goh FRANZCR

4. Noel Atkinson FRACS

5. Tim Iseli FRACS

$(1,2,4,5)$ Dept of Surgery, University of Melbourne, Royal Melbourne Hospital, Grattan St, Parkville 3050 Ph 93427000 Email iselient@hotmail.com

(1, 3) Dept of Radiology, Royal Melbourne Hospital, Grattan St, Parkville 3050

The corresponding author is not a recipient of a research scholarship.

The paper is not based on a previous communication to a society or meeting.

Figures included: 3

Tables included: 0

Abstract word count: N/A

Main article word count: 746

Corresponding author:

This is the author manuscript accepted for publication and has undergone full peer review but has not been through the copyediting, typesetting, pagination and proofreading process, which may lead to differences between this version and the Version of Record. Please cite this article as doi: $10.1111 /$ ans. 13689

This article is protected by copyright. All rights reserved. 
Dr Dayu Gai

Email: dayu.gai@gmail.com

Postal address: Level 1, Radiology Department, Royal Melbourne Hospital, VIC 3052

Phone: +6193427000

A 67 year old female presented with 5 months of right ear blockage. Past medical history was significant for surgically resected breast cancer. There was no past history of traumatic injury to the neck.

On examination, the patient had a bulging mass pushing the right soft palate forwards. Blood pressure was $120 / 70 \mathrm{mmHg}$. There was no abnormality on neurological examination.

Initial imaging with MRI of the neck and brain showed a $35 \mathrm{~mm} \times 45 \mathrm{~mm} \times 55 \mathrm{~mm}$ well circumscribed lesion centred within the right prestyloid parapharyngeal space (Figure 1). The lesion was heterogeneously hypointense on T1 and T2 weighted imaging with moderate diffuse contrast enhancement. A provisional diagnosis of parapharyngeal salivary gland tumour was made.

A plan was made to attempt US guided FNA via a cervical approach posterior to the right submandibular gland. Doppler ultrasound showed hazy signal dropout internally on all sequences, suggestive of a slow flow varix. FNA was withheld and the patient proceeded to CT angiographic assessment.

The CT angiogram demonstrated a sharply circumscribed mass arising $20 \mathrm{~mm}$ above the origin of the right internal carotid artery (ICA) and finishing $9 \mathrm{~mm}$ below the base of skull (Figure 2). The mass opacified concurrently with the proximal right ICA, suggesting a carotid aneurysm.

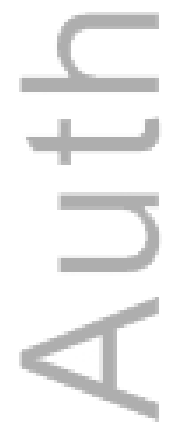


A right carotid angiogram was performed to further delineate the anatomy of the lesion (Figure 3). From the bifurcation, there was $20-30 \mathrm{~mm}$ of normal ICA, followed by a large saccular aneurysm. There was no evidence of out-flow vessel at the top or apex of the aneurysm.

The patient proceeded to open surgical repair with aneurysm excision and saphenous vein graft. Intraoperatively, two openings emptying from the right ICA into the aneurysmal sac were found, each separated by $20 \mathrm{~mm}$. Histopathology confirmed marked arteriosclerotic fibrointimal thickening and fibrosis, consistent with aneurysm wall. The patient awoke with no neurologic deficit and is well one month after surgery.

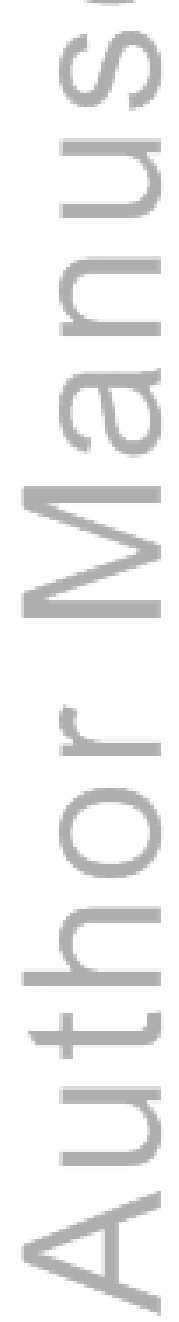




\section{Discussion}

The parapharyngeal space is divided into a pre- and post-styloid region by the fascia running from the styloid process to the tensor veli palatini muscle. Prestyloid pharyngeal tumours are most commonly salivary tumours, usually arising from the deep lobe of parotid. Approximately $80 \%$ are benign while $20 \%$ are malignant. The most common histological subtype is a pleomorphic adenoma (1). Malignant tumours, such as adenocarcinoma or adenoid cystic carcinoma are uncommonly seen (2).

Routine workup of parapharyngeal tumours is with CT and MR imaging. Ultrasound guided FNA usually has a limited role due to the deep nature of the parapharyngeal space. In a subset of patients with large, accessible parapharyngeal tumours, FNA can play a role in diagnosis.

On CT, pleomorphic adenomas are typically homogeneous and hypodense relative to native salivary gland tissue with variable enhancement (3). They are well-circumscribed, homogeneous masses on MR imaging, with low T1 and high T2 signal intensity(4). These lesions typically enhance homogeneously with gadolinium, although larger tumours can show variable enhancement. CT features of internal carotid aneurysms include the presence of a well-defined mass, with peripheral eggshell calcification(5). Early arterial enhancement suggests an arterial vascular type of lesion. Aneurysms may display high central signal intensity on T1 and T2 weighted MR imaging, corresponding to true arterial flow(5). Low signal may surround it, corresponding to surrounding thrombus within the aneurysm. In our case study, the lesion was well-circumscribed and displayed heterogeneous hypointense signal on MR. Only on CT, did the lesion display classic early arterial enhancement (Figure 2). Furthermore, displacement of the pterygoid plates was thought to be consistent with an arterial aneurysmal lesion.

Extracranial ICA aneurysms are uncommon and represent $0.2-0.4 \%$ of all operated aneurysms. Common risk factors for development include atherosclerosis and traumatic neck injury(6). Less common risk factors include connective tissue disorder (Ehlers-Danlos syndrome, fibromuscular

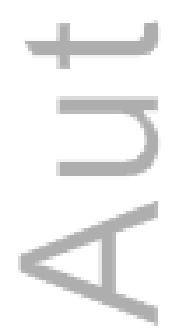


dysplasia), infection and radiotherapy(7). Patients typically present with a pulsatile cervical or parapharyngeal mass which may also have bruit. Occasionally, the lesion may be asymptomatic. Central nervous system symptoms due to thrombo-embolism are common, and may include hemiplegia, hemiaesthesias, unilateral visual loss and dysphasia. CT angiogram can be used to assess for ICA aneurysm, although digital subtraction angiography is the gold standard for investigation. DSA is used for pre-operative planning and can give vital information about location, type of aneurysm and the presence of further lesions.

In conclusion, ICA aneurysms may have a similar radiologic appearance to salivary tumours. Consideration must always be given to the possibility of aneurysmal disease in the differential diagnosis of parapharyngeal space lesions in order to ensure that the correct operation is performed by the most appropriate sürgeon, minimising the risk for potentially catastrophic complications.

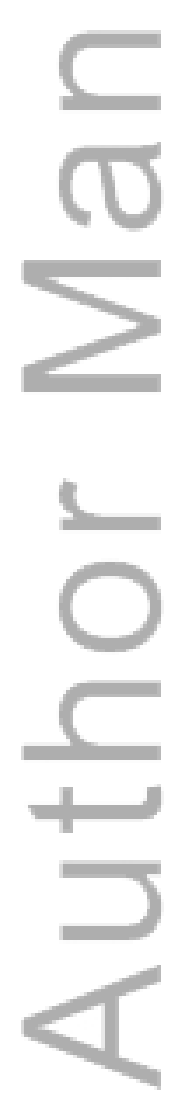




\section{References}

\section{0}

1. Tom BM, Rao VM, Guglielmo F. Imaging of the parapharyngeal space: anatomy and pathology. Critical reviews in diagnostic imaging. 1991;31(3-4):315-56. PubMed PMID: 2036175.

2. Shin JH, Lee HK, Kim SY, Choi CG, Suh DC. Imaging of parapharyngeal space lesions: focus on the prestyloid compartment. AJR American journal of roentgenology. 2001 Dec;177(6):1465-70. PubMed PMID: 11717108.

3. Howlett DC, Kesse KW, Hughes DV, Sallomi DF. The role of imaging in the evaluation of parotid disease. Clinical radiology. 2002 Aug;57(8):692-701. PubMed PMID: 12169280.

4. Habermann CR, Arndt C, Graessner J, Diestel L, Petersen KU, Reitmeier F, et al. Diffusion-weighted echo-planar MR imaging of primary parotid gland tumors: is a prediction of different histologic subtypes possible? AJNR American journal of neuroradiology. 2009 Mar;30(3):591-6.

\section{PubMed PMID: 19131405.}

5. Munoz A, Campollo J, Vergas J. Bilateral internal carotid aneurysms presenting as a nonpulsatile parapharyngeal mass: complementary diagnosis by CT, MR imaging, and digital subtraction angiography. AJNR American journal of neuroradiology. 2001 May;22(5):864-6. PubMed PMID: 11337329.

6. Shimizu T, Sakakura Y, Yamagiwa M, Hori M, Yuasa H, Murata M. Aneurysm of the extracranial carotid artery. Archives of otolaryngology-head \& neck surgery. 1986 Feb;112(2):203-6. PubMed PMID: 3942627.

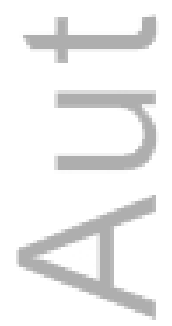


7. DeFatta RJ, Verret DJ, Bauer P. Extracranial internal carotid artery pseudoaneurysm. International journal of pediatric otorhinolaryngology. 2005 Aug;69(8):1135-9. PubMed PMID: 15936830.

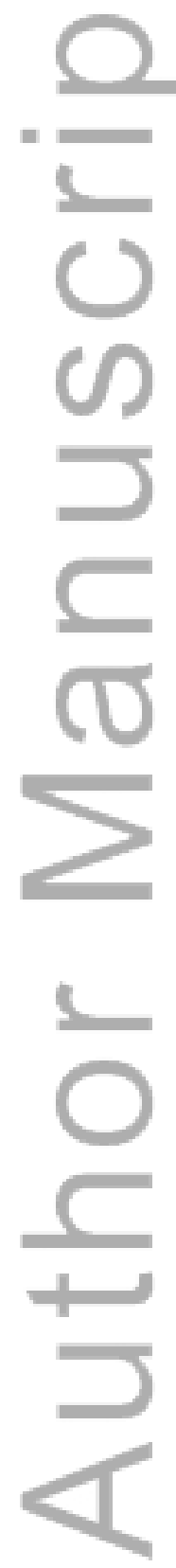

This article is protected by copyright. All rights reserved. 


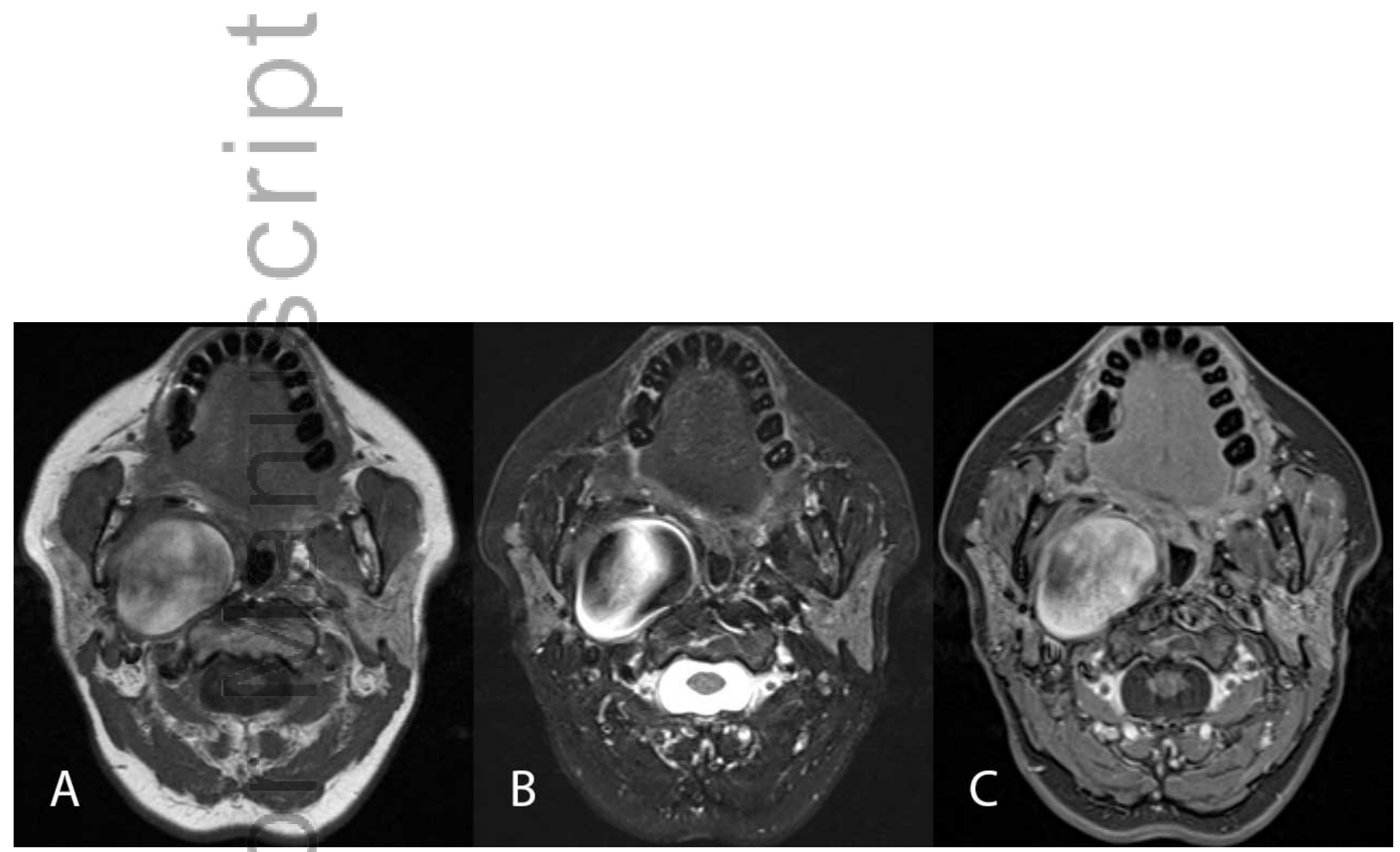

Figure 1.jpg

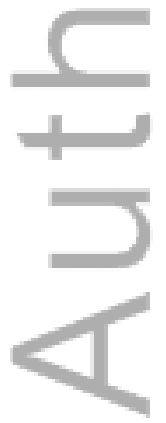

This article is protected by copyright. All rights reserved. 


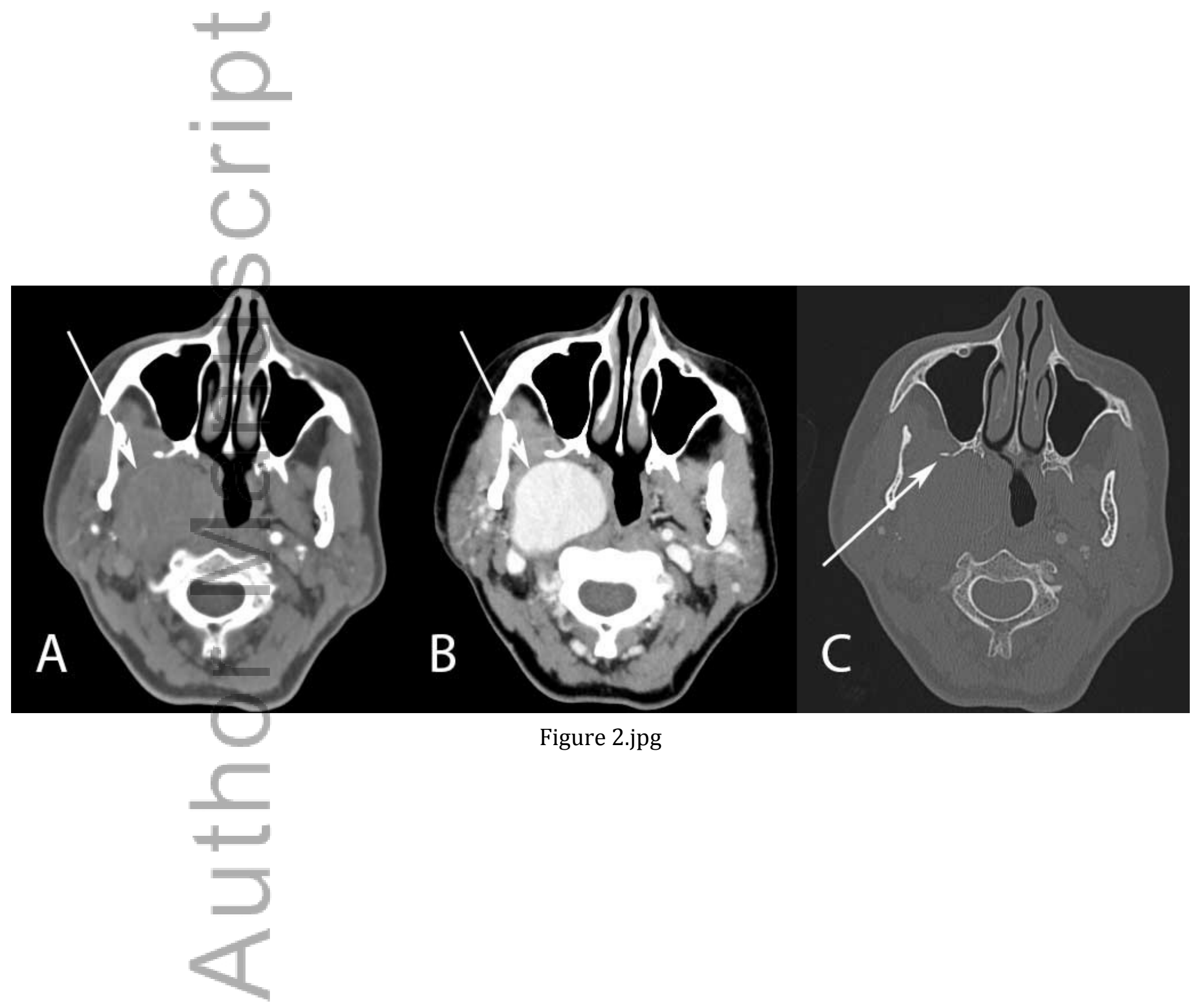

This article is protected by copyright. All rights reserved. 

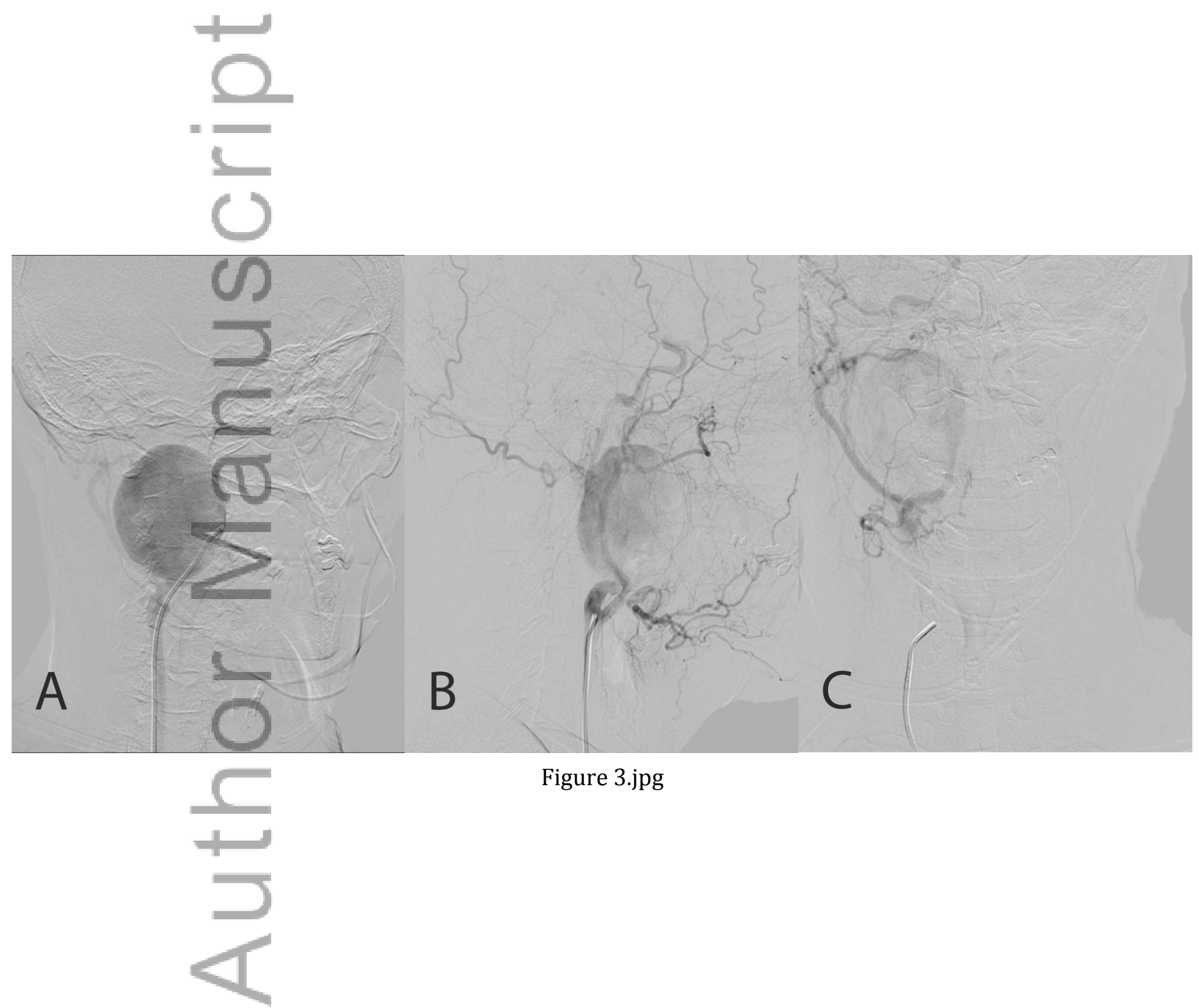

Figure 3.jpg

This article is protected by copyright. All rights reserved. 


\section{University Library}

\section{- M M N E R VA A gateway to Melbourne's research publications}

Minerva Access is the Institutional Repository of The University of Melbourne

Author/s:

Gai, D;Burgess, C;Goh, C;Atkinson, N;Iseli, T

Title:

Extracranial internal carotid aneurysm masquerading as a parapharyngeal tumour

Date:

2018-10-01

Citation:

Gai, D., Burgess, C., Goh, C., Atkinson, N. \& Iseli, T. (2018). Extracranial internal carotid aneurysm masquerading as a parapharyngeal tumour. ANZ JOURNAL OF SURGERY, 88 (10), pp.E736-E738. https://doi.org/10.1111/ans.13689.

Persistent Link:

http://hdl.handle.net/11343/291849 